\title{
SUPERFÍCIES DE TITÂNIO MODIFICADAS POR OXIDAÇÃO À PLASMA EM CÁTODO OCO
}

\author{
Marco Aurélio Medeiros da Silva \\ Universidade Federal do Rio Grande do Norte, Prog. de Pós-Graduação do CCS, Campus \\ Universitário, Lagoa Nova, Natal, RN, Brasil. CEP: 59072-970. \\ marcoaureliobucofacial@yahoo.com.br \\ Paulo Victor de Azevedo Guerra \\ Universidade Federal do Rio Grande do Norte, Departamento de Engenharia Biomédica, \\ Lagoa Nova, Natal, RN, Brasil. CEP: 59072-970. \\ paulovictorguerra@gmail.com \\ Ricardo Alexsandro de Medeiros Valentim \\ Universidade Federal do Rio Grande do Norte, Departamento de Engenharia Biomédica, \\ Campus Universitário, Lagoa Nova, Natal, RN, Brasil. CEP: 59072-970. \\ ricardo.valentim@ufrnet.br \\ Hélio Roberto Hékis \\ Universidade Federal do Rio Grande do Norte, Departamento de Engenharia de Produção, \\ Campus Universitário, Lagoa Nova, Natal, RN, Brasil. CEP: 59072-970. \\ hekis1963@gmail.com \\ Karilany Dantas Coutinho \\ Universidade Federal do Rio Grande do Norte, Departamento de Engenharia Biomédica, \\ Campus Universitário, Lagoa Nova, Natal, RN, Brasil. CEP: 59072-970. \\ karilany@ufrnet.br \\ Clodomiro Alves Junior \\ Universidade Federal Rural do Semi-Árido, Departamento de Física, \\ Costa e Silva, Mossoró - RN, 59625-900. \\ clodomiro.jr@gmail.com \\ Custódio Leopoldino de Brito Guerra Neto \\ Universidade Federal do Rio Grande do Norte, Departamento de Engenharia Biomédica, \\ Campus Universitário, Lagoa Nova, Natal, RN, Brasil. CEP: 59072-970. \\ custodioguerra@yahoo.com.br
}

\begin{abstract}
RESUMO
Uma nova metodologia de oxidação de superfícies de implantes de titânio foi desenvolvida com o intuito de remover previamente os óxidos primários formados espontaneamente durante a usinagem de peças de titânio. Com o objetivo de solucionar esse problema, utilizou-se neste trabalho o plasma como fonte energética tanto na remoção desses óxidos, como na oxidação de superfície de titânio. Nesse sentido, discos de Titânio tiveram seus óxidos previamente removidos por plasma com atmosfera de $50 \% \mathrm{Ar}+50 \% \mathrm{H}_{2}$ seguidos da oxidação pela técnica de descarga por cátodo oco. A oxidação foi realizada numa mistura de argônio (60\%) e oxigênio (40\%) até atingir a pressão de $220 \mathrm{~Pa}$ durante $60 \mathrm{~min}$ a $500^{\circ} \mathrm{C}$. Em seguida caracterizou-se as superfícies oxidadas e controle por difração de Rx (X-Ray diffraction), microscopia de força atômica AFM (Atômic Force Microscopy) e microscopia eletrônica de varredura (SEM) (Scanning Electron Microscopy). Resultados obtidos por X-Ray rasante indicou que o processo de remoção dos óxidos foi eficaz, reduzindo $\mathrm{TiO}_{2}$ para Tia. Com relação ao processo de oxidação, verificou-se que houve um aumento de $61 \%$ para $76 \%$ na concentração de $\mathrm{O}_{2}$ e a amostra oxidada apresentou-se rica em
\end{abstract}


óxidos como $\mathrm{TiO}_{2}$. Na caracterização por AFM as amostras oxidadas apresentaram defeitos nas superfícies com geometria variada para picos e vales. As diferenças topográficas entre a superfície oxidada e controle são discutidas em termos das dimensões médias dos poros e dos parâmetros de rugosidade $\mathrm{Ra}, \mathrm{Rp}$ e Rz. Ensaios biológicos foram também realizados com o intuito de observar a adesão e proliferação celular. No SEM observou-se espraiamento celular, uma maior quantidade de projeções de filopódios e diferenças morfológicas nas células das amostras oxidadas em comparação com a amostra controle. Na proliferação celular as células mostraram uma preferência por superfícies oxidadas onde o número de células aderidas foi comparativamente superior, em relação à amostra controle. Concluímos que o processo foi eficiente na remoção dos óxidos primários bem como na oxidação da superfície do titânio.

PALAVRAS-CHAVE: Oxidação a plasma, Tratamento de superfície de titânio, Osteoblastos, Implantes dentais, Biomateriais.

\title{
TITANIUM SURFACES MODIFIED BY PLASMA OXIDATION IN HOLLOW CATHODE
}

\begin{abstract}
A new methodology for oxidation of titanium implant surfaces was developed to remove primary oxides formed spontaneously during titanium parts machining. With the aim of resolving the problem, this study used plasma as an energy source both in removing these oxides and oxidizing the titanium surface. In this respect, Ti disks had their oxides removed by plasma in an atmosphere of $50 \%$ Air $+50 \% \mathrm{H} 2$, followed by oxidation using the hollow cathode discharge technique. Oxidation was performed for $60 \mathrm{~min}$ at $500^{\circ} \mathrm{C}$, in a mixture of argon $(60 \%)$ and oxygen (40\%) until reaching a pressure of $220 \mathrm{~Pa}$. Next, the oxidized surfaces were characterized by XRD (X-Ray diffraction), AFM (Atomic Force Microscopy) and SEM (Scanning Electron Microscopy). Results obtained by grazing incidence X-Ray indicated that the oxide removal process was effective, reducing $\mathrm{TiO} 2$ to

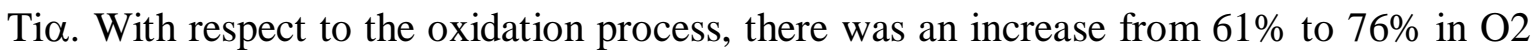
concentration and the oxidized sample was rich in oxides such as $\mathrm{TiO} 2$. Characterization of AFM revealed that the oxidized samples exhibited surface defects with varied geometry for peaks and valleys. The topographic differences between the oxidized surface and the control are discussed in terms of mean pore dimensions and roughness parameters ( $\mathrm{Ra}, \mathrm{Rp}$ and $\mathrm{Rz}$ ). Biological assays were also conducted to observe adhesion and cell proliferation. SEM showed cell spreading, a larger number of filopodial projections and morphological differences in the cells of oxidized samples when compared to the control sample. In cell proliferation, cells showed a preference for oxidized surfaces where the number of adherent cells was comparatively higher than in the control sample. We concluded that the process was efficient in removing primary oxides as well as in oxidizing titanium surfaces.
\end{abstract}

\section{KEYWORDS:}

Plasma oxidation, Titanium surface treatment, Osteoblasts, Dental implants, Biomaterials. 


\section{SUPERFÍCIES DE TITÂNIO MODIFICADAS POR OXIDAÇÃO À PLASMA EM CÁTODO OCO}

\section{INTRODUÇÃO}

O sucesso clínico dos dispositivos biomédicos implantados depende da interação entre as células do organismo e a superfície do material utilizado [1]. Implantes de titânio têm sido utilizados há mais de quarenta anos e com sucesso, como substitutos da raiz dentária [1,2]. Um dos fatores determinantes para que ocorra a osseointegração diz respeito à superfície dos implantes [3]. A resposta biológica está diretamente relacionada às propriedades físico-químicas das superfícies. Tanto a morfologia quanto a rugosidade da superfície podem ter influência sobre a adesão, proliferação e diferenciação celular [4]. A adesão dos osteoblastos sobre a superfície dos implantes é necessária para que as células recebam os sinais para induzir sua proliferação. As rugosidades presentes na superfície não só facilitam a retenção de células osteoblásticas, como também permitem que elas migrem sobre a superfície do implante, através de osseocondução [5,6].

Processos relevantes para a funcionalidade dos implantes, tais como a adsorção de proteínas, interação célula-superfície, desenvolvimento celular e tecidual na interface entre o organismo e o implante dependem de propriedades superficiais como topografia, química de superfície, carga superficial e molhabilidade [7,8]. A topografia da superfície dos implantes diz respeito ao grau de rugosidade e à orientação das irregularidades da superfície. O modo como estas estruturas influenciam a reparação e a regeneração é o objetivo de várias publicações e estudos nos últimos anos [5,6].

Tendo em vista a importância da topografia e das propriedades químicas das superfícies dos implantes, a indústria procura controlar essas propriedades durante a fabricação desses dispositivos. Nos últimos 20 anos, um grande número de sistemas de implantes com diferentes topografias de superfície foi introduzido no mercado. Porém, muito pouco é divulgado ou se conhece sobre as características físico-químicas da superfície dos implantes, limitando-se as informações contidas e m bulas e catálogos técnicos, especialmente no Brasil [1,5,6].

Muitos tratamentos de superfícies têm sido empregados nos implantes dentários com o intuito de melhorar suas propriedades, potencializando a fixação celular ao implante, aumentando assim, a osseointegração [3]. Porém, para que seja possível tirar conclusões a respeito da resposta óssea em superfícies modificadas, fazem-se necessárias caracterizações das mesmas e correlaciona-las com resultados biológicos e clínicos. Assim, para o desenvolvimento de um material clinicamente aplicável, a modificação de superfície é uma ferramenta eficaz que pode aumentar sua biofuncionalidade e promoção do crescimento de espécies [9]. Diversas são as técnicas (métodos mecânicos, químicos e físicos) utilizadas com o objetivo de modificar a superfície e portanto, garantir uma resposta biológica funcionalmente adequada. Dentre os métodos físicos destaca-se o tratamento a plasma [10]. Sua utilização permite modificar as propriedades da superfície de materiais através da criação de novos grupos funcionais, mudanças topográficas bem como adição/subtração química à superfície [11].

Neste contexto, superfícies de titânio submetidas ao plasma revelaram que variações na microtopografia pode afetar a proliferação de células osteoblásticas [12]. Diante disso, titânio foi modificado por oxidação a plasma usando a técnica de descarga por cátodo oco. Esta técnica foi utilizada por apresentar uma alta densidade de íons resultando numa maior cinética de formação da camada de óxidos. Também devido às características citadas, a técnica não compromete termicamente o núcleo do dispositivo 
embora a temperatura na superfície seja alta. Este estudo fornece dados que podem gerar subsídios na elaboração de novas estratégias para obtenção de uma superfície com melhor biocompatibilidade, usando uma técnica versátil e ecologicamente correta.

\section{MATERIAIS E MÉTODOS}

Utilizou-se 40 discos de titânio grau II (ASTM F86), com 10 mm de diâmetro e 1.5 $\mathrm{mm}$ de espessura. Todos os discos foram submetidos a ensaios metalográficos e a um rígido protocolo de limpeza utilizado por Alves et al. (2005), em 3 etapas: detergente enzimático (DEIV 3E), álcool e água bidestilada por 10 minutos em agitação ultrassônica. Após a limpeza, os discos foram utilizados no desenvolvimento de um estudo visando à redução por plasma dos óxidos passivos presentes em superfícies de titânio. A remoção desses óxidos formados espontaneamente é de extrema importância na fabricação de implantes uma vez que esses óxidos passivos são formados geralmente na etapa de usinagem, contendo assim contaminantes. Verificou-se que o plasma da mistura Ar-50\% e $\mathrm{H}_{2}-50 \%$ foi à condição mais eficaz na remoção de óxido de titânio e por isso ela foi utilizada no presente trabalho. A remoção foi realizada numa câmara de aço inoxidável hermeticamente fechada (reator de plasma), com $300 \mathrm{~mm}$ de diâmetro e $300 \mathrm{~mm}$ de comprimento, fonte de tensão DC variável e sistema de vácuo para receber o tratamento de superfície, Fig. 1a.
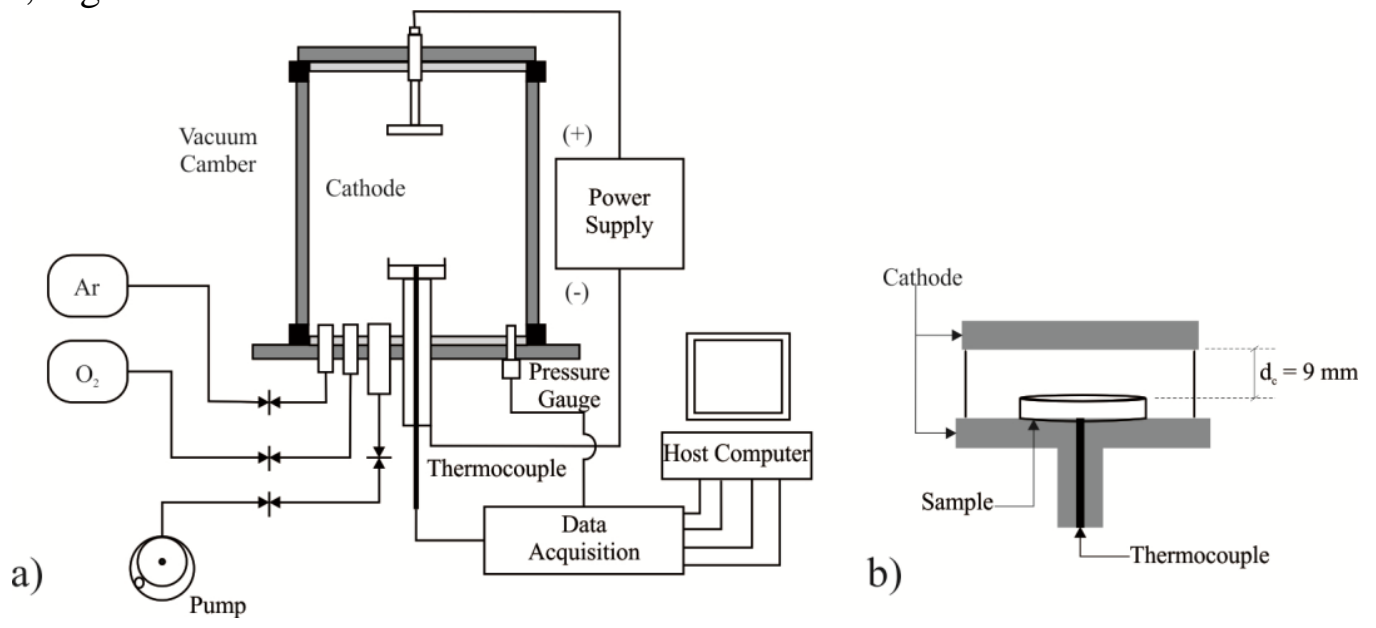

Figura 1 - Diagrama esquemático do reator de plasma (1a) e configuração do eletrodo para produzir a descarga por cátodo oco (1b).

Para o tratamento de oxidação foi utilizado o mesmo equipamento utilizado na remoção dos óxidos modificando apenas a configuração do eletrodo para produzir a descarga por cátodo oco (Fig. 1b). A distância entre cátodos utilizada foi de $9 \mathrm{~mm}$, pelo fato deste valor ter resultado em maior eficiência energética para a faixa de pressão utilizada. A fonte para polarização utilizada é de corrente contínua, com tensão de saída ajustável até $1200 \mathrm{~V}$ e corrente máxima de $1.5 \mathrm{~A}$. Um termopar, do tipo cromel/alumel, foi inserido na parte inferior da porta amostra para o controle da temperatura da amostra durante o processo de oxidação. A pressão interna da câmara foi medida através de sensor de membrana capacitiva, tipo baratron (Edwards) com fundo de escala de 1000-300 Pa.

$\mathrm{O}$ procedimento de oxidação das amostras de titânio em descarga por cátodo oco 
foi realizado utilizando-se uma mistura de argônio (60\%) e oxigênio (40\%), resultando em um fluxo constante de $12 \mathrm{sccm}$ (standard cubic centimeters per minute) para o argônio e 8 sccm para o oxigênio, até atingir a pressão de $220 \mathrm{~Pa}$. O processo foi mantido a $500^{\circ} \mathrm{C}$ durante 60 minutos [13].

\section{CARACTERIZAÇÃO DAS SUPERFÍCIES DE TITÂNIO}

As amostras foram caracterizadas por difração de raios $\mathrm{X}$ usando a geometria Bragg-Brentano e a geometria Seemann-Bohlin (incidência rasante de $5^{\circ}$ ). A primeira geometria obtém-se informações micro estruturais de regiões mais profundas da amostra; a segunda, incidência rasante, obtém-se informações da superfície. O ensaio foi realizado em um difratômetro Siemens D-5000, radiação $\mathrm{Cu}-\mathrm{K} \alpha$, com ângulo de varredura (20) de $30^{\circ}$ a $80^{\circ}$ para a geometria de Bragg-Brentano e; de $33^{\circ}$ à $43^{\circ}$ para a incidência rasante. Para investigação da topografia das superfícies dos discos de Titânio, foi utilizado um microscópio de força atômica, modelo MFP - 3D AFM Asylum Research e para estudo da química da superfície utilizou-se o equipamento de XPS, Multilab ESCA3000. As imagens obtidas foram analisadas utilizando-se o Software imagem Pro Plus $6.0 \mathrm{com}$ mensuração por área de $5 \times 5 \mu \mathrm{m}^{2}$.

Para avaliação da molhabilidade das amostras de titânio foi utilizada a técnica da gota séssil num goniômetro DSA 10 Krüss Technology, utilizando-se gotas de $5 \mu 1$ dos seguintes líquidos: água destilada, glicerol (GLY), cujas polaridades variam de polar a apolar. As medidas dos ângulos de contatos foram efetuadas em 5 regiões diferentes, usando uma amostra oxidada e outra sem tratamento para cada líquido utilizado. Os valores resultantes das medidas foram representados pelas médias aritméticas e desvio padrão.

\section{ENSAIO BIOLÓGICO}

\section{TESTE IN VITRO COM CULTURA DE CÉLULAS (HOB)}

Foram utilizados osteoblastos humanos (linhagem HOB). As células foram descongeladas, cultivadas em meio de cultura Dulbecco Medium Eagle (DMEM) com baixa concentração de glicose (Sigma Chem Co, EUA), suplementado com 10\% de soro fetal bovino (Soromed, Brasil). O ph do meio de cultivo foi ajustado para 7.2. O cultivo foi realizado em garrafas de poliestireno de $25 \mathrm{~cm}^{2}$ (Corning, EUA) e as células mantidas em estufa a $37^{\circ}$ em uma atmosfera úmida com $5 \%$ de $\mathrm{CO}_{2}$. Ao atingirem confluência, as células foram descoladas do fundo das garrafas por incubação em solução de tripsina + EDTA por no máximo 5 minutos, a temperatura ambiente, sendo a reação interrompida pela adição de gotas de soro. As células resultantes foram aspiradas e submetidas à centrifugação (1500rpm/10min), e lavadas por 2 vezes em PBS (solução Salina Fosfatada Tamponada), à mesma velocidade e tempo. O pellet resultante foi submetido á avaliação de densidade e viabilidade celular com azul de tripan [14].

\section{ENSAIO DE ADESÃO OSTEOBLASTOS}

$\mathrm{O}$ ensaio ${ }^{3} \mathrm{H}$-Timidina foi usado para avaliar a adesão celular, sendo feita a monitoração do DNA genômico, pois a proliferação celular depende de sua síntese. A ${ }^{3} \mathrm{H}$ Timidina incorporada ao DNA tem sido usada como marcador de replicação. As células presentes no pellet foram incubadas em meio completo (DMEM + soro) contendo ${ }^{3} \mathrm{H}$ Timidina [10]. Após duas horas de incubação parte das células foi centrifugada, lavada em DMEM sem soro, re-suspensa em PBS, contada em câmara de Neubauer. Os vials, 10 no 
total, contendo cada um $1.5 \times 10^{6}$ células.ml, foram levados à contagem de radioatividade em aparelho de cintilação líquida, aparelho PerkinElmer modelo LS50B. A contagem no aparelho resultou que $1.5 \times 10^{6}$ células.ml, equivalência de $1.134 \pm 0.154 \mathrm{cpm}$ (contagens por minuto). Desta forma, $1.134 \mathrm{cpm}$ (100\% de radioatividade) foram incubados nos 6 discos de Titânio, sendo 3 oxidadas e 3 controles. Após o período de 1, 3 e 6 horas de incubação, as células marcadas com ${ }^{3} \mathrm{H}$-Timidina que se encontravam associadas a cada uma das superfícies foram rompidas/lisadas e o produto resultante levado à contagem em cintilador. A radiatividade associada a cada uma das superfícies foi medida.

\section{ENSAIO DE PROLIFERAÇÃO CELULAR}

Foi realizado o ensaio MTT para análise da proliferação celular como descrito por Mosmann [15]. Foram utilizadas 27 amostras sem tratamento e 27 amostras oxidadas por plasma para determinação da proliferação das células osteoblásticas durante 3, 7 e 11 dias, utilizando 3 discos para cada período analisado.

Uma solução de MTT a $1 \mathrm{mg} / \mathrm{ml}$ foi preparada pela dissolução do sal em meio D-MEM pobre, sem a adição de soro fetal bovino e antibiótico, $1 \mathrm{ml}$ da solução de MTT foi adicionado em cada amostra na placa de 24 poços. Após 4 horas de incubação a $37^{\circ} \mathrm{C}$ em atmosfera úmida com $5 \%$ de $\mathrm{CO} 2$, o meio foi retirado e $1 \mathrm{ml}$ da solução solubilizadora, que consiste em etanol absoluto, foi adicionada para lisar as células e dissolver os cristais de formazan. A placa foi mantida em agitação constante durante cinco minutos no escuro. Posteriormente, $100 \mathrm{ml}$ do sobrenadante resultante foram transferidos para uma placa de 96 poços e a densidade ótica foi medida em 570nm de comprimento de onda. Os valores foram analisados em porcentagem de absorbância em relação ao controle.

\section{MICROSCÓPIO ELETRÔNICO DE VARREDURA (SEM)}

Após os ensaios de proliferação, as amostras de foram sequencialmente lavadas com PBS estéril, $\mathrm{pH} 7.2$, fixadas com glutaraldeído a $2.5 \%+4 \%$ de paraformaldeído, durante 60 minutos à temperatura ambiente. Foram depois lavadas três vezes (10 min cada) com o mesmo tampão, pós-fixadas em tetróxido de ósmio a $1 \%$ feita em tampão de cacodilato de sódio $0.1 \mathrm{M}$ durante 15 minutos à temperatura ambiente. Lavou-se exaustivamente com PBS estéril. As amostras resultantes foram fixadas, desidratadas com etanol e secadas (Balzers, modelo CPD 30) utilizando $\mathrm{CO}_{2}$ como líquido de transição. Elas foram, em seguida, revestidas com uma camada fina de ouro atomizados para a análises em um microscópio eletrônico de varredura (SEM), (JEOL, JSM modelo 5310), operando a 20 $\mathrm{kV}$.

\section{RESULTADOS E DISCUSSÕES}

O comportamento ósseo integrador dos implantes de titânio pode ser melhorado através da compreensão das características da superfície dos implantes, tais como: determinação dos efeitos da energia de superfície, composição, rugosidade e topografia sobre as respostas biológicas iniciais tais como: proliferação celular, diferenciação, produção de matriz extracelular, maturação e calcificação óssea [16].

$\mathrm{Na}$ Fig. 2a é apresentado o resultado usando a geometria Bragg-Brentano, em que os difratogramas para as duas amostras são aparentemente iguais. Isso acontece porque o filme óxido é muito fino e a informação que esse tipo de técnica fornece é em maior profundidade, ou seja, do substrato de titânio. Para obter informação mais detalhada das 
fases dos filmes superficiais foi utilizada a geometria de Seemann-Bohlin, com ângulo de incidência de $5^{\circ}$, para a faixa de 33 a $43^{\circ}$ (Fig.2b). Observe que a amostra sem tratamento

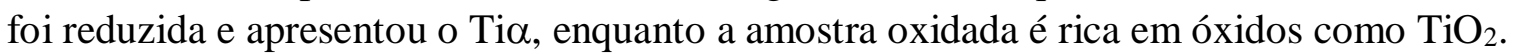

a)

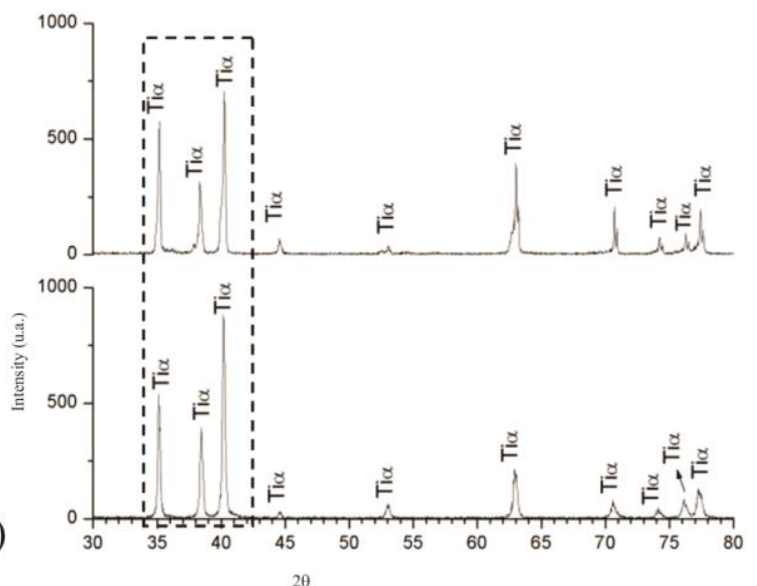

b)

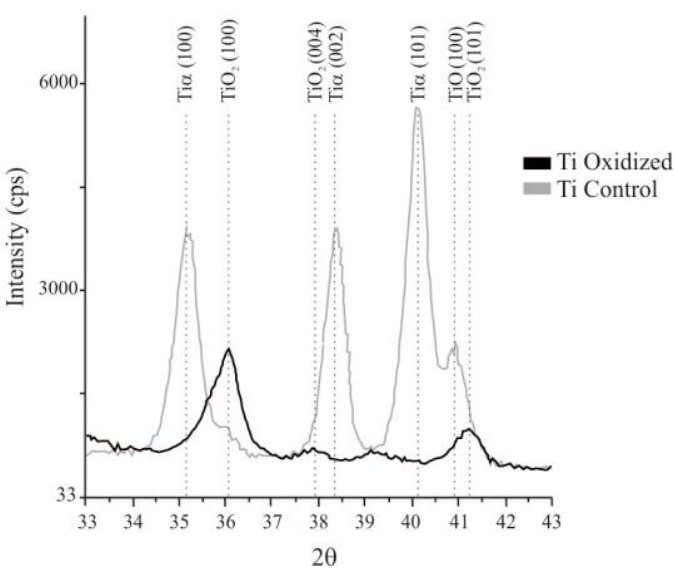

Figura 2 - Difração de raios-X da amostra controle e oxidada usando (2a) geometria Bragg-Bretano e (2b) geometria de Seemann-Bohlin (incidência rasante).

Além da composição e estrutura cristalina, grandezas relacionadas com a topografia e molhabilidade da superfície possuem influência sobre a resposta biológica numa superfície $[17,18]$.

A importância da atividade química da superfície na determinação da configuração das proteínas, bem como a taxa e quantidade de proteínas adsorvidas, tem sido explorada por diversos pesquisadores, porém o limite químico e topográfico ideal para adesão proteica não é estabelecido [14,17,19].

Tendo como foco a dimensão celular, a topografia da superfície passa a apresentar um papel de maior relevância que a rugosidade propriamente dita, no que se refere às respostas biológicas, ou seja, orientação, migração de células e arranjo de citoesqueleto celular [20,21]. O parâmetro de média aritmética $(\mathrm{Ra})$ apesar de muito reportado por muitos autores, não é um parâmetro incisivo sobre o conhecimento da topografia de uma superfície, nem descreve adequadamente a rugosidade superficial uma vez que superfícies arredondadas e pontiagudas não são distinguidas, e superfícies com diferentes topografias podem compartilhar valores em comum, não definindo com clareza o comportamento do relevo superficial [22,23]. Por definição, Ra é usado para detectar variações gerais em altura de perfil global, entretanto uma alteração no parâmetro Ra não é representativa para avaliar todas as variações de rugosidade, ou seja, alterações na distribuição dos picos, presença ou ausência destes que venham a ocorrer com pouca frequência e vales fundos. $\mathrm{O}$ parâmetro Rz é definido como a diferença de altura comum entre os cinco picos mais altos e os cinco vales de aspereza mais baixos, enquanto que o parâmetro Rp é definido como a altura de máximo do ponto mais alto de aspereza sobre a linha base [24].

Entretanto, uma opção seria a utilização dos parâmetros $\mathrm{Rz}$ e, Rp, bem como a razão $\mathrm{Rp} / \mathrm{Rz}$, pois estes dados podem se apresentar como uma alternativa para determinação do perfil topográfico (Fig. 3) tendo em vista que, desta forma esta relação torna-se de grande importância para uma avaliação mais confiável na determinação do formato da superfície, pois uma razão superior a 0.5 indica a presença de uma superfície composta de picos pontiagudos, enquanto que para valores inferiores a 0.5 caracteriza-se uma superfície com picos arredondados [23]. 
Com base nos valores médios de rugosidade apresentados na Tabela 1, observa-se que as amostras oxidadas apresentaram um incremento no valor de Ra quando comparado com a amostra controle. Entretanto para estas amostras, o desvio padrão foi elevado sendo este fato atribuído ao processo de tratamento ao qual a amostra foi submetida, onde há a possibilidade do fenômeno de re-sputtering ou até mesmo o processo promover no material nano-deformações não homogêneas em sua extensão, sendo este o motivo de não se considerar este parâmetro como incisivo na análise de rugosidade para este tipo de processo. Desta forma a utilização da razão $\mathrm{Rp} / \mathrm{Rz}$, torna-se mais efetivo, reportando uma tendência de topografia mais arredondada para as amostras oxidadas e pontiagudas para as amostras controle.

Tabela 1. Valores de Rugosidade das amostras oxidadas e controle

\begin{tabular}{c|c|c|c|c}
\hline \multirow{2}{*}{ Amostra } & $\mathrm{Ra}$ & $\mathrm{Rp}$ & $\mathrm{Rz}$ & \multicolumn{2}{c}{$\begin{array}{c}\mathrm{Rp} / \mathrm{Rz} \\
\mathrm{nm}\end{array}$} \\
\cline { 5 - 6 } & $\mathrm{nm}$ & $\mathrm{nm}$ & $\mathrm{nm}$ & $\mathrm{nm}$ \\
\hline Oxidadas & $81.39 \pm 22.9$ & $204.66 \pm 61.26$ & $447.52 \pm 113.02$ & $0.45 \pm 0.05$ \\
Controle & $30.43 \pm 8.96$ & $176.87 \pm 38.46$ & $352.81 \pm 66.85$ & $0.5 \pm 0.04$ \\
\hline
\end{tabular}

A topologia das amostras controle pode ser visualizada observando-se a (Fig.3a), onde a superfície da amostra apresenta uma topologia sem definição entre picos e vales. Entretanto para as amostras oxidadas (Fig.3b) observa-se que o tratamento com plasma promoveu uma alteração na superfície das amostras, onde um relevo bastante característico pode ser visualizado. Nestas amostras as topografias da superfície revelam uma ocorrência de picos e vales com geometria variada, e sem um padrão pré-definido. As dimensões das cavidades foram calculadas com base nas imagens dessas superfícies conforme representado na (Fig. 3c).

a)
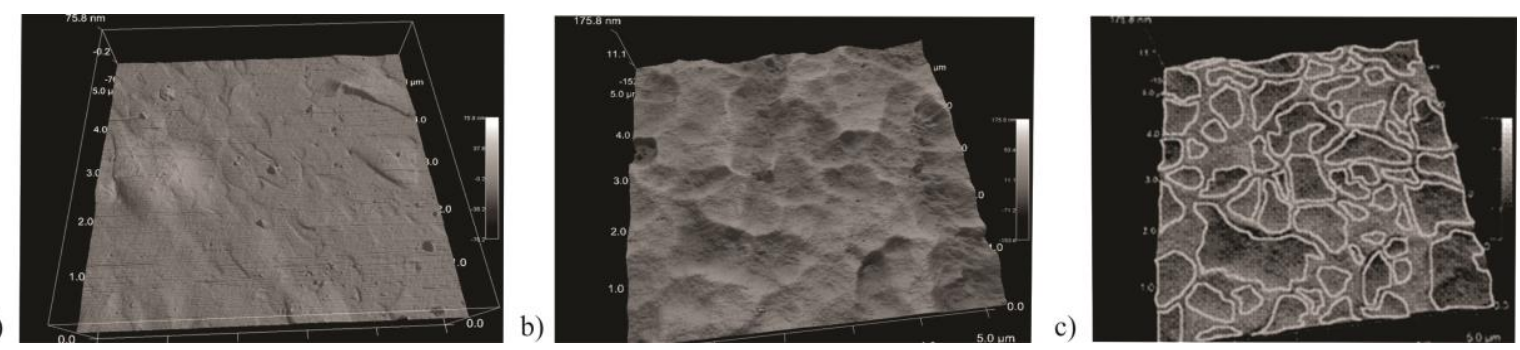

Figura 3 - Topografia da superfície: Amostra Controle (3a). Amostras oxidadas (3b);

\section{Área delineada da topografia (3c).}

As alterações superficiais observadas tanto nos resultados de rugosidade como na microscopia de força atômica são decorrentes da interação de íons e outras espécies contidas no meio plasmático, onde ocorrem simultaneamente desde o bombardeamento destas até a transferência térmica, aumentando assim o gradiente de temperatura da amostra, e produzindo assim defeitos superficiais (Fig. 3b) [10,13]. Os valores de cavidade da amostra oxidada, calculados a partir das crateras delineadas (Fig. 3c) encontram-se na faixa de 0.487 a $1.56 \mathrm{~nm}^{2}$, sendo o valor médio de $0.248 \mathrm{~nm}^{2}$. Embora estes valores sejam inferiores ao tamanho celular, receptores de membrana associados internamente com elementos do citoesqueleto, as protusões dirigem-se pontualmente a cada elevação da 
superfície do material constituindo assim focos de adesão. A topografia das amostras oxidadas torna-se mais propícia para a adesão celular, visto que a literatura reporta que, o diâmetro dos receptores das membranas celulares apresenta dimensões de 8 a $12 \mathrm{~nm}$, por conseguinte a dimensão de cavidade poderá apresentar influenciar no comportamento celular, devido ao fato de que as células percebem suas proximidades através de protusões com escala de valor semelhantes [21]. No entanto, ainda não é bem claro se o comportamento das células é afetado diretamente pela topografia em escala nano ou se somente responde às orientações das proteínas pré-adsorvidas, ou até mesmo se está relacionado a ambos os parâmetros simultaneamente $[17,18,19,20]$.

Tabela 2. Valores do ângulo de contato para gotas séssil de diferentes líquidos em superfícies de titânio oxidado e controle.

\begin{tabular}{l|l|l}
\hline \multicolumn{1}{c}{ Ti Controle } & \multicolumn{1}{c}{ Ti Oxidadas } \\
\hline $\mathrm{H}_{2} \mathrm{O}$ destilada & $36.0 \pm 0.2$ & $37.2 \pm 0.1$ \\
DMSO & $48.2 \pm 0.3$ & $59.7 \pm 0.2$ \\
GLY & $42.6 \pm 0.2$ & $50.5 \pm 0.3$ \\
DIIODO & $55.3 \pm 0.2$ & $69.8 \pm 0.2$ \\
$\alpha B R N$ & $61.3 \pm 0.3$ & $75.5 \pm 0.2$ \\
\hline
\end{tabular}

Com relação às medidas de ângulo de contatos das amostras estudadas, os resultados obtidos indicam que para a medida realizada com água, as amostras oxidadas, apresentaram um comportamento inesperado, ou seja, não houve diferença estatística nos valores de angulo de contato quando comparada com a amostra controle. Este comportamento pode ser atribuído à alteração do estado energético, bem como ao fato dos defeitos de ordem nanométricas oriundos do tratamento superficial não apresentarem influência sobre o líquido de caráter apolar, caso da água. Porém, à medida que os líquidos testados apresentaram um caráter mais polar, DMSO, GLY, DIIODO e $\alpha \mathrm{BR}$, observou-se uma maior afinidade para as amostras controle, ver Tabela 2, pois o espalhamento da gota para esses líquidos foi mais pronunciado. Portanto, esse resultado pode sugerir que a amostra modificada por oxidação a plasma apresenta uma superfície mais compatível com um liquido apolar e consequentemente esta característica poderá influenciar adsorção proteica e posteriormente adesão celular [17,25,26]. Esse comportamento também pode estar associado à alteração da energia livre da superfície e/ou alterações dos parâmetros topográficos de rugosidade e microtextura [27].

Tabela 3. Medidas de ${ }^{3} \mathrm{H}$-timidina associadas às células HOB após 1 hora, 3 horas e 6 horas de interação com amostras oxidadas e controle.

\begin{tabular}{c|c|c|c}
\hline \multirow{2}{*}{ SUPERFÍCIES } & \multicolumn{3}{|c}{ TEMPO DE INCUBAÇÃO } \\
& 1 hora & 3 horas & 6 horas \\
\cline { 2 - 4 } & $72.3 \%$ & $78.5 \%$ & $77.2 \%$ \\
Ti Controle & $73.9 \%$ & $88.4 \%$ & $90.6 \%$ \\
\hline Ti Oxidadas &
\end{tabular}


Os resultados obtidos durante o ensaio da adesão celular indicam que o tratamento superficial não promoveu alteração significativa na primeira hora como observado na (Tabela 3). Entretanto após as três horas o percentual de associação à superfície aumentou para $88.4 \%$ e após seis horas atingiram $90.06 \%$ de associação à superfície oxidada. Enquanto que na superfície controle $78.5 \%$ e $77.2 \%$ das células se associaram a esta superfície. Em todos os tempos, as células mostraram uma preferência por superfícies tratadas por plasma onde o número de células aderidas foi comparativamente superior, em relação à amostra controle. Atribui-se este comportamento as rugosidades superficiais promovidas pela oxidação por plasma em catodo oco. Sabe-se que a rugosidade topográfica deve ser controlada, isso porque as células necessitam de pontos de ancoragem presentes na superfície para que possam aderir e proliferar [28]. Se o valor da rugosidade for muito menor que o diâmetro dos filopódios, não existirão locais adequados para a adesão, acontecendo o mesmo para valores muito elevados; não haverá local para a ancoragem e a célula iria reconhecer uma depressão, sem grandes detalhes topográficos, como uma superfície lisa, semelhante à amostra controle [28,29,30].

Assim, a adesão e a proliferação celular não devem ser avaliadas apenas quanto a sua amplitude, mas também quanto à organização topográfica $[3,31,32]$. O corpo celular é, predominantemente, observado nos vales e as expansões citoplasmáticas projetam-se em direção aos picos e, ao mesmo tempo, os osteoblastos passam a se dividir rapidamente.

Ambas as topografias analisadas provocam alterações e estimulam o citoesqueleto, promovendo uma maior interação entre as células e a matriz proteica já aderida $[3,32,33]$.

Os resultados sugerem uma preferência celular pela superfície oxidada devido à mesma possuir propriedades físico-químicas e características compatíveis com uma melhor resposta biológica.

Apesar da quantidade de células aderidas terem sido muito semelhante para ambos os grupos na primeira hora, a diferença maior pode ser expressa tendo se como base a morfologia das células osteoblásticas conforme observado na análise de microscopia eletrônica de varredura (Fig. 4 e Fig. 5).

a)

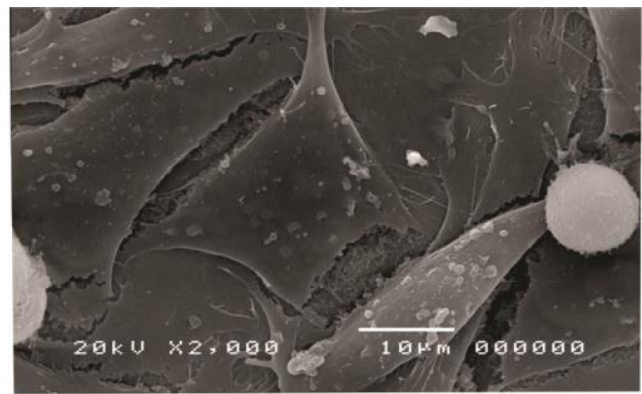

b)

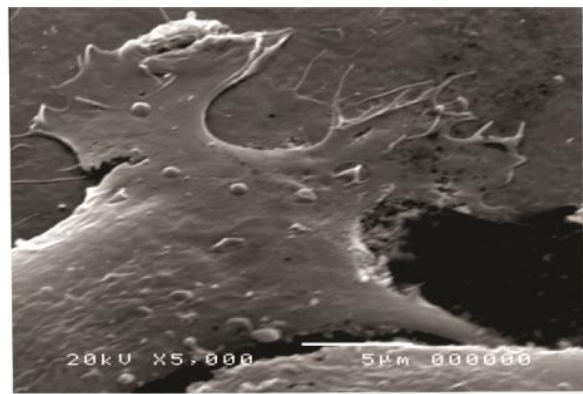

Figura 4 - MEV da amostra controle: Aparência poligonal das células na amostra controle (4a); Característica de espalhamento da amostra controle (4b). 
a)

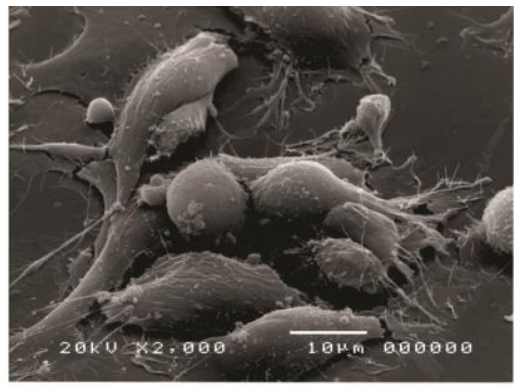

b)

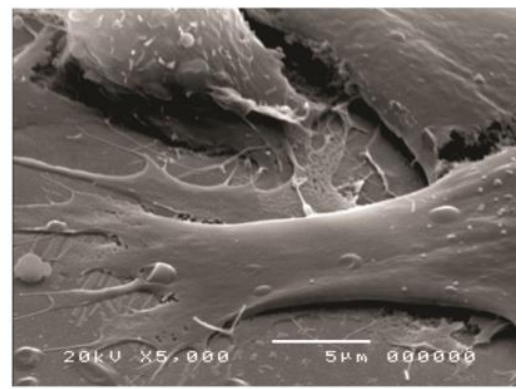

Figura 5 - Característica morfológica das células em amostra com tratamento (5a); Presença de múltiplos filopódios com dimensões semelhantes às áreas delineadas na topografia da superfície $(5 \mathrm{~b})$.

As células aderidas na superfície das amostras controle (Fig. 4a) e (Fig. 4b), apresentam uma morfologia achatada, com prolongamentos celulares curtos, necessitando grande esforço para se espraiar pela topografia, já que não encontram estruturas tridimensionais, como acontece na superfície rugosa da amostra oxidada que permite a acomodação celular, por haver um amplo contato com a superfície [34]. Neste caso, as células logo entram em contato com alguma estrutura, sem necessidade de esforços laterais para se espraiar. Na superfície rugosa da amostra oxidada, as células apresentam uma forma mais alongada, poligonal e com prolongamentos celulares mais longos, (Fig. 5a) e (Fig. 5b) [28,29]. A aleatoriedade das irregularidades, a organização espacial presente nas superfícies oxidadas, propiciam vales mais amplos entre as elevações em forma de platôs e picos que alojam, por comparação de tamanho, os osteoblastos e seus prolongamentos. Os resultados obtidos podem ser um indicativo de que, provavelmente as diferenciações morfológicas das células aderidas sofreram alguma influência das características superficiais das amostras estudadas, sendo este comportamento reportado pela literatura [35,36,37,38,39,40]. Porém estudos neste campo revelam que, apesar de não existir um consenso em quantificar um padrão ideal, o tipo de topografia tem uma significativa influência no crescimento celular, indicando que deve existir um limite crítico de rugosidade para uma boa proliferação celular [16,17]. Entretanto não há na literatura, referência à existência clara de uma correlação linear entre os parâmetros de rugosidade, morfologia e amplitude da superfície [41,42].

Alguns autores enfatizam em seus trabalhos que a diferenciação osteoblástica, proliferação e produção de matriz extracelular, assim como produções de fatores de crescimentos locais são afetadas pela topografia de superfície e rugosidade, e que essas variáveis exercem controle sobre fenótipos celulares em diversas linhagens, como fungos, células epiteliais, leucócitos, entre muitas outras, inclusive osteoblastos [19,37,39,42].

Já está estabelecido na literatura que essas modificações da superfície do Ti irão promover alterações na interação célula-biomaterial [14]. O arranjo de conformação de rugosidade observado na amostra oxidada favoreceu a adesão e espraiamento dos osteoblastos.

A proliferação celular também foi afetada pelo tratamento de oxidação por plasma, quando comparadas à superfície controle. Modificações na composição da atmosfera gasosa que compõe o plasma, temperatura, baixa pressão e do tempo de tratamento promoveram um aumento da proliferação de células cultivadas sobre as superfícies de Ti tratadas. A comprovação é mostrada na Fig. 6 onde o resultado da proliferação celular foi medido pela densidade óptica no ensaio do MTT. Observa-se que a amostra controle apresentou nos primeiros três dias uma proliferação semelhante à amostra oxidada. No sétimo e no decimo dia a proliferação mostrou-se maior na amostra oxidada quando 
compara a amostra controle. As células mostraram uma preferência por superfícies oxidadas onde o número de células aderidas foi comparativamente superior, em relação à amostra titânio controle.

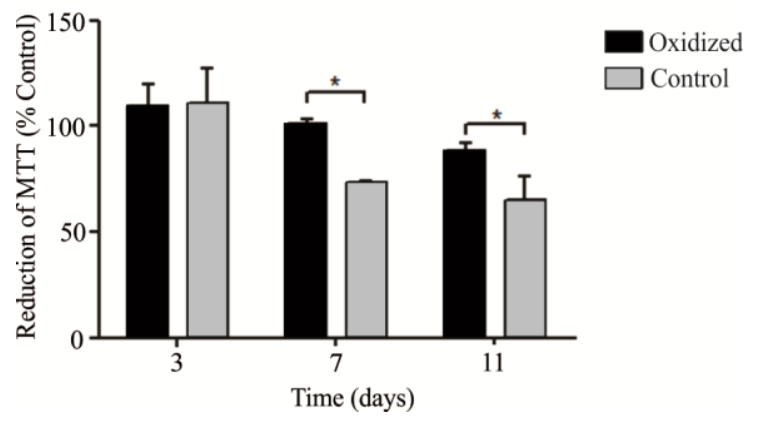

Figura 6 - Proliferação celular na superfície oxidada e superfície controle (ST) e controle negativo $(\mathrm{CN})$, análise da variância Turkey pós-teste $(\mathbf{p}<0.05)$.

\section{CONCLUSÃO}

Baseado no que foi relatado e exposto, conclui-se que:

1. O processo foi eficiente na remoção dos óxidos primários bem como na oxidação da superfície do titânio.

2. No processo de oxidação verificou-se que houve um aumento na concentração de $\mathrm{O}_{2}$ na superfície além de diferenças topográficas entre a superfície oxidada e não oxidada.

3. No microscópico eletrônico de varredura (SEM) observou-se diferenças morfológicas celulares para ambas as superfícies. Uma maior quantidade de projeções de filopódios foi visualizada nas amostras oxidadas em comparação com a amostra controle.

4. As células aderidas na superfície da amostra controle apresentaram uma morfologia achatada, com prolongamentos celulares curtos, necessitando grande esforço para se espraiar pela topografia.

5. As células mostraram uma preferência por superfícies oxidadas onde o número de células aderidas foi comparativamente superior, em relação à amostra controle.

\section{AGRADECIMENTOS}

Ao LAIS - Laboratório de Inovação Tecnológica em Saúde e ao LAPLASMA da Universidade Federal do Rio Grande do Norte. 


\section{REFERÊNCIAS BIBLIOGRÁFICAS}

[1] M. LONG, H. J. RACK. Biomaterials. 19 (1998) 1621.

[2] B. KASEMO. SURFACE SCIENCE. 500 (2002) 656.

[3] A. B. NOVAES JR, S. L. SOUZA, R. R. BARROS, K. K. PEREIRA, G. IEZZI, A. PIATTELLI. Brazilian Dental. Journal. 21 (2010) 471.

[4] R. B. L. BUENO, P. ADACHI, L. M. S. CASTRO-RAUCC, A. L ROSA, A. NANCI, P. T. OLIVEIRA. Brazilian Dental Journal. 22 (2011) 179.

[5] M. B. ROSA, T. ALBREKTSSON, C. E. FRANCISCHONE, H. O. SCHWARTZ FILHO, A. WENNERBERG. Dental Press Implantology. 6 (2012) 76.

[6] M. B. ROSA, T. AlbREKTSSON, C. E. FRANCISCHON, H. O. SCHWARTZ FILHO, A. WENNERBERG. Dental Press Implantology. 2 (2012) 44.

[7] T. ALBREKTSSON, A. WENNERBERG. In Journal Prosthodont. 17 (2004) 536.

[8] T. ALBREKTSSON, A. WENNERBERG. Int Journal Prosthodont. 17 (2004) 544.

[9] S. BAUER, P. SCHMUKI, K. V. D. MARK, J. PARK. Progress in Materials Science. 58 (2013) 261.

[10] C. AlveS JR, C. L. B. GUERRA NETO, G.H.S. MORAIS, C. S . SILVA, V. HAJEK. Surface \& Coatings Technology. 194 (2005) 196.

[11] J.C. SÁ, R.A. BRITO, C. E. MOURA, N. B. SILVA, M. B. M. ALVES, C. ALVES JR. Surface \& Coatings Technology. 203 (2009) 1765.

[12] C. L B. GUERRA NETO, M. A. M. SILVA, C. ALVES, JR. Surface Engineering, 25 (2009) 146.

[13] M. A. M Silva, A. E. MARTINELli, C. ALVES JR., R. M. NASCIMENTO, M. P. TÁVORA, C. D. VILAR. Surface \& Coatings Technology. 200 (2006) 2618.

[14] K. ANSELME. Biomaterials. 21 (2000) 667.

[15] T. MOSMANN. Journal Immunological Methods. 65 (1983) 55.

[16] K. KIESWETTER, Z. SCHWARTZ, T. W. HUMMERT, D. L. COCHAN, J. SIMPSON, D. D. DEAN. Journal Biomedical Materials Research. 32 (1996) 55.

[17] X. ZHU, J. CHEN, L. SCHEIDELER, R. REICHL, J. GEIS-GERSTORFER. Biomaterials 25 (2004) 4087.

[18] A. F. VON RECUM, T. G. VAN KOOTEN. Journal Biomaterials Science, Polymer Edition. 7 (1996) 181.

[19] P. ROACH, D. EGLIN, K. ROHDE, C. C. PERRY. Journal Materials Science: Materials in Medicine. 18 (2007) 1263. 
[20] A. CURTIS, C. WILKINSON. Biomaterials.18 (1997) 1573.

[21] R.A. GITTENS, R. O. NAVARRETE, T. MCLACHLAN, Y. CAI, S. L. HYZY, J. M. SCHNEIDER, Z. SCHWARTZ, K.H. SANDHAGE, B. D. BOYAN. Biomaterials. 33 (2012) 8986.

[22] F. RUPP, L. SCHEIDELER, N. OLSHANSKA, M. WILD, M. WIELAND, J GEISGERSTORFER. Biomaterial. 25 (2005) 1429.

[23] S. A. WHITEHEAD, A. C. SHEARER, D. C. WATTS, N.H.F. WILSON. Journal of Oral Rehabilitation. 22 (1995) 421.

[24] C. N. ELIAS, Y. OSHIDA, J. H. LIMA, C. A. MULLER. Journal on Mechanical Behavior of Biomedical Materials. 1 (2008) 234.

[25] J. BICO, THIELE U, QUÉRÉ D. Colloids and Surfaces A: Physicochemical and Engineering Aspects. 206 (2002) 41.

[26] W. ZHOU, X. ZHONG, X. WU, L. YUAN, Z. ZHAO, H. WANG, Y. XIA, Y. FENG, J. HE, W. CHEN. Surface \& Coatings Technology. 200 (2006) 6155.

[27] T. MEKAYARAJJANANONTH, S. WINKLER. Journal Oral Implantology. 25 (1999) 230.

[28] K. ANSElME, M. BIGERELlE, B. NOEL, E. DUFRESNE, D. JUDAS, A. IOST, P. HARDOUIN . Journal of Biomedical Materials Research. 49 (2000) 155.

[29] S.F. ALVES, T. WASSALL. Brazilian Oral Research. 23 (2009)131.

[30] D.D. DELIGIANNI, N. KATSALA, S. LADAS, D. SOTIROPOULOU, J. AMEDEE, Y.F. MISSIRLIS. Biomaterials. 22 (2001)1241.

[31] I. ABRAHAMSSON, T. BERGLUNDH, E. LINDER, N. LANG, J. LINDHE. Clinical Oral Implants Research. 15 (2004) 381.

[32] D.M. D.EHRENFEST,L.VAZQUEZ, Y.J. PARK,G. SAMMARTINO, J.P. BERNA RD. Journal Oral Implantology. 37 (2011) 525.

[33] C. ARNHART, G.DVORAK, C.TREFIL, C. HUBER, G. WATZEK, W. ZECHNER. Clinical Oral Implants Research. 24 (2013) 1049.

[34] C. GALli, S. GUIZZARDI, G. PASSERI, D. MARTINI, A.TINTI, G. MAURO,G.M. MACALUSO. Journal of Periodontology. 76 (2005) 364.

[35] J. Y. MARTIN, Z. SCHWARTZ, T. W. HUMMET, D. M. SCHRAUB, J. SIMPSON, J. LANKFORD, D. D. DEAN, D. L. COCHRAN, B. D. BOYAN. Journal of Biomedical Materials Research. 29 (1995) 389.

[36] A. WENNERBERG, T. ALBREKTSSON. Clinical Oral Implants Research. 20 
(2009) 172.

[37] B. CHEHROUDI, T. R. GOULD, D. M. BRUNNETE. Journal of Biomedical Materials Research. 23 (1989) 1067.

[38] C. ERIKSSON, J. LAUSMAA, H. NYGREN. Biomaterials. 22 (2001) 1987.

[39] H. C. HOCH, R. C. STAPLES, B. WHITEHEAD. Science. 235 (1987) 1659.

[40] B. ZIMERMAM, T. VOLBERG, B. GEIGER. Cell Motil and the Cytoskeleton. 2 (2004) 151.

[41] L. PONSONNET, V. COMTE, A. OTHMANE, C. LAGNEAU, M. LiSSAC, N. JAFFREZIC. Materials Science and Engineering. 21 (2002) 157.

[42] K. ANSELME, M. BIGERELLE. Acta Biomaterialia. 1 (2005) 211. 